\title{
INFORMATION QUALITY AS A DETERMINANT OF TASK-TECHNOLOGY FIT IN USING COMMUNICATION TECHNOLOGY FOR SIMPLE TASK
}

\author{
ChongWoo Park, Georgia Gwinnett College, cpark@ggc.edu \\ Arjan Raven, aredraven@gmail.com
}

\begin{abstract}
Theories of task-technology fit have been used to evaluate the fit between different tasks and technologies in the IS context. These theories focus only on task types and technology characteristics as determinants of task-technology fit, which in turn impacts performance. Information quality, which is an important deliverable when someone uses information technology for a task, has not been discussed as a possible determinant. In this study, we argue that given the importance of information and knowledge content in modern systems, information quality can contribute to the fit evaluation as another determinant of fit. We empirically tested a task technology fit model, applying a "fit as matching" perspective in the context of a simple task and communication technology. The results show that the addition of information quality in the model increases the explanatory power for the fit and the ultimate dependent variable, performance. The findings point to the importance of information quality in modern systems.
\end{abstract}

Keywords: Task-Technology Fit, Information Quality, Task Match, Simple Task, Communication Technology

\section{INTRODUCTION}

Measuring information systems (IS) success objectively is an enduring theme in IS research. Examples of theories and models are the technology acceptance model (TAM), the IS success model, and the task-technology fit (TTF) theories. Whereas TAM focuses on individual acceptance of technology based on usefulness and ease of use [8] and the IS success model focuses on system use and user satisfaction based on system quality, information quality, and service quality [9], the TTF theories focus on the fit between different types of task and technology [43]. While both TAM and the IS success model have been extensively tested in empirical studies and extended in numerous ways $[10,38,39]$, the TTF theories have received relatively less research attention.

One reason for the dearth in research attention could be the absence of a unified model of TTF, which leads to confusion in conceptualizing and measuring TTF. Unlike TAM and the IS Success model, which have wellestablished, generally agreed-upon constructs to measure, TTF theories have different approaches to defining key constructs and relationships between tasks and technologies [45]. Those different approaches include media richness theory [6], adaptive structuration theory [12], the fit-appropriation model [11], and the technology-to-performance chain [24], and fit profiles [43]. Despite the different approaches to conceptualizing TTF, they share four major constructs of TTF - task, technology, fit, and performance.

Even with the four major constructs identified, however, the model of TTF may still have some problems when applied in the context of modern information systems. In traditional systems, the emphasis was very much on the processing and creation of data. These days a lot of systems rely not just on data, but also on information and knowledge. They don't just produce information; they also store and manage it. We argue that the quality of information dealt with in the information systems should be considered as an independent factor in evaluating the fit between task and information systems. A user may not find a good fit between their task and the information system without good quality of information used and/or created.

In this study, we adopt a general model of task-technology fit [43], and suggest information quality as another determinant of task-technology fit. We test how information quality contributes to the evaluation of fit between a simple task and a communication technology and to the overall explanatory power of the model. 


\section{INFORMATION QUALITY AND TASK-TECHNOLOGY FIT}

The nature of information quality has changed. At the time of Delone and McLean's 1992 [9] article on the IS success model, the focus was on the quality of the information system output, i.e., the reports that were created by the system. "Information quality is concerned with such issues as the relevance, timeliness, and accuracy of information generated by an information system" [9]. In modern systems we see a shift from focusing solely on the output of the system to looking at the output and the contents of an information system. A course management system is meaningless without its documents. A customer relationship management system is essentially useless without the knowledge that is embedded in it. As knowledge workers we use systems that have information and knowledge in them. We make the systems more valuable over time as we add and update its contents. A wiki can gain value over time if it is used and if knowledge is added and updated. Similarly, it can lose value if it is static.

Over the years, the importance of the creation, sharing and application of information and knowledge has been shown in a number of studies. For example, Wasko and Faraj [40] looked at knowledge sharing; Gold et al. [40] studied knowledge management capabilities and their impact on organizational effectiveness; and Gray and Meister [26] studied the impact of knowledge sourcing on learning outcomes. On the systems side, the need to capture and store information and knowledge is reflected in terms such as knowledge management systems [1], electronic knowledge repositories [28, 25] and transactive memory systems [5].

Information quality no longer concerns just what is created by the system, it also describes critically important contents that is stored and managed in the system. This is a fundamental difference, and the role of information quality has been expanded for modern systems. This increased role needs to be reflected in the TTF models.

\section{Task-Technology Fit Theory}

Theories of task-technology fit (TTF) suggest that a better fit between technology and task will lead to better performance $[24,43]$. Figure 1 shows the general model of task-technology fit.

There are two major streams of research in TTF. One is based on work by Goodhue and Thompson [21-23, 24], and the other finds its origin in conceptualizations of TTF by Zigurs and Buckland [43, 44, 45]. While the former has employed quantitative approaches including survey [24, 13,31] and experimental design [23, 17], the latter is characterized by a more qualitative approach $[43,36]$ and a focus on group support systems $[11,17]$. In addition, the concept of TTF has been expanded in multiple ways, for instance, through the combination of TTF with TAM [13, 36,29 ], the addition of appropriation [11] and the inclusion of precursors of utilization [35]. Each of the streams has found evidence for the importance of a match between task and technology for systems performance. In our study we followed the conceptualization of TTF by Zigurs and Buckland [10].

TTF is a function of how the dimensions or features of technology and the characteristics of a task interact or intersect [45]. In the remainder of this section we discuss definitions by Zigurs and Buckland [43] of task, technology, and TTF. One approach to understanding and defining a task is based on its complexity. Campbell [3] defined the complexity level of a task through four dimensions: outcome multiplicity, solution scheme multiplicity, conflicting interdependence, and solution scheme/outcome uncertainty. Zigurs and Buckland [43] have defined five task categories based on different combinations of those four basic dimensions of task complexity suggested by Campbell [[3]. In general, they define a group task as "the behavior requirements for accomplishing stated goals, via some process, using given information, [43]." The five task categories are simple, problem, decision, judgment, and fuzzy tasks. According to Zigurs and Buckland [43], "[s]imple tasks are primarily characterized by a single outcome and solution scheme, problem tasks by solution scheme multiplicity, decision tasks by outcome multiplicity, judgment tasks by conflicting interdependence or uncertainty, and fuzzy tasks primarily by the joint presence of outcome multiplicity and solution scheme multiplicity."

Zigurs and Buckland's [43] theoretical study on TTF provided three technology dimensions specifically for group support systems: communication support, process structuring, and information processing; each of which represents a different aspect of group work that is to be supported. We believe that the three dimensions are also applicable to information systems for communication in general since such systems support group communications between two or more users. 
Communication support is defined as "... any aspect of the technology that supports, enhances, or defines the capability of group members to communicate with each other [43]." We will use the term "communication technology" to refer to any tool that is used to support communication.

Six perspectives on fit have been identified in the strategy literature [37] - fit as matching, as covariation, as gestalts, as moderation, as mediation, and as profile deviation. Zigurs and Buckland [43] employed the idea of fit as profile deviation to conceptualize fit into a GSS environment, and defined TTF as "ideal profiles composed of an internally consistent set of task contingencies and GSS elements that affect group performance [43]." Building upon the fit concept as an ideal profile, they suggest fifteen fit profiles from the five task categories and three technology dimensions (See Table 1).

Table 1. Fit Profiles of Task Categories and Technology Dimensions (adapted from Zigurs and Buckland [43])

\begin{tabular}{|l|c|c|c|}
\hline Task Category & Communication Support & Process Structuring & Information Processing \\
\hline Simple & High & Low & Low \\
\hline Problem & Low & Low & High \\
\hline Decision & Low & High & High \\
\hline Judgment & High & Low & High \\
\hline Fuzzy & High & Medium & High \\
\hline
\end{tabular}

In this study, we employ Zigurs and Buckland's [43] notion of fit as profile deviation to explore fit profiles between task categories and technology dimensions. Among the fifteen profiles shown in Table 1, we test the fit between a simple task and communication support technologies, and we investigate how the fit affects individual performance.

\section{Research Model}

While IS researchers share some common understanding of the TTF concept, they have adopted different ways to evaluate the TTF. Goodhue and Thompson [24] used sixteen dimensions to measure the TTF. Dishaw and Strong [13] computed the TTF by matching the task characteristics to supporting functionality of the maintenance technology. Mathieson and Keil [31] used subjects' task performance with time and accuracy components to measure the TTF. Zigurs and her colleagues [44] evaluated the TTF qualitatively using fit profiles, and found that a match between the GGS and the task positively affects performance. In this study, we adopt the concept of task match to measure the TTF. Task match is defined as "the ability of system functionality to serve user task needs [14]."

System users need some information to complete their tasks. Without the information stored inside of it, the system cannot be used, and therefore there will not be a fit between the task and the system. Thus, information of high quality is a necessary condition in evaluating the fit between a task and a system, and the higher the quality of information, the better the fit. Now, there needs to be a fit between task, technology, and information.

The role of information in determining the fit between a task and technology has been discussed in the IS literature. DeLone and McLean's IS success model [9] supports the link between information quality and fit as task match. According to DeLone and McLean's update on the IS success model [10], information quality leads to individual impact. Individual impact has multiple dimensions: task productivity, task innovation, customer satisfaction, and management control. The task productivity dimension, which is defined as the extent to which an application improves the user's output [10], is very close to the concept of fit as task match. Thus, we argue that information quality would play a role as another determinant of fit in the TTF model, and formulate the following hypothesis.

Hypothesis 1: Information quality will positively affect the fit when an individual uses a communication technology to perform a simple task.

In his re-specified version of the IS success model, Seddon [34] suggests two general perceptual measures of the net benefits from IS use - perceived usefulness and user satisfaction, which are dependent variables led by system 
quality and information quality. In addition, he employs perceived usefulness in his IS success model as an individual performance measure following Davis's [7] definition, i.e., "the degree to which a person believes that using a particular system has enhanced his or her job performance." If a system does not have information of sufficient quality, then it will not be useful. Thus, we argue that information quality would affect an individual's perception of usefulness for IS use as an indicator of his/her performance, and state the following hypothesis.

Hypothesis 2: Information quality will positively affect the individual performance when an individual uses a communication technology to perform a simple task.

In addition to the two hypotheses above, we also test the original links from communication technology to fit, and to performance in the general TTF model. Previous studies on the general TTF model have theoretically argued the links from technology to fit and from fit to individual performance [24, 43]. In addition, Dishaw and Strong [13] empirically established that the characteristics of technology including availability affect the TTF, and that the TTF determines perceived usefulness as an individual performance. Thus, we state the following two hypotheses from the general TTF model.

Hypothesis 3: The quality of a communication technology will positively affect the fit when an individual uses the communication technology to perform a simple task.

Hypothesis 4: The task-technology fit will positively affect the individual performance when an individual uses a communication technology to perform a simple task.

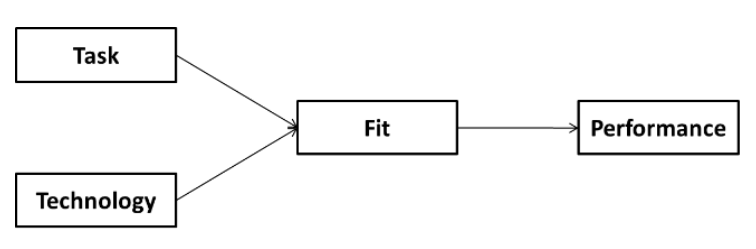

Figure 1. General Model of Task Technology Fit

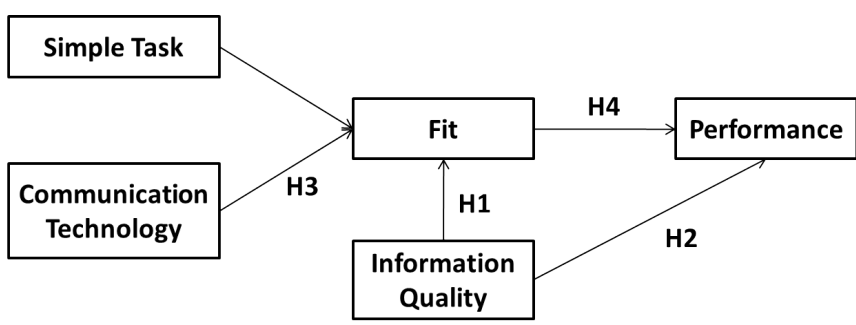

Figure 2. Research Model: Task-Technology Fit with Information Quality

\section{RESEARCH METHOD}

The research model in Figure 2 was tested through a survey of users of WebCT Vista, a web-based course management and discussion system. We selected WebCT Vista as the communication technology for this research because the tasks that students perform in WebCT Vista are characterized by single outcomes and single solution scheme, which reflects the simple tasks in a communication technology. Examples of such tasks are posting a completed assignment, contributing to a discussion board, sending and receiving email, and document retrieval. In addition, according to the fit profiles in Table 1, the choice of the simple task implies that the type of technology has to be communication support since the other technologies (process structuring and information processing) have only low support for simple tasks. Thus, tasks in WebCT Vista appear to be a good example of simple tasks in a communication technology.

The questionnaires were distributed to 112 undergraduate users of WebCT Vista in a management information systems course at a southern university in 2009-2010. The respondents received bonus points for completing the survey. We assume that non-response bias did not occur in this survey research because all of the WebCT Vista users that we asked to participate completed the survey.

A survey instrument was developed based on items used in previous studies. Several items, discussed below, were dropped from the instrument, and some were rewritten to reflect the study's context. The final survey consists of 4 demographic questions and 23 seven-point Likert-type items $(1=$ very strongly disagree, $2=$ strongly disagree, $3=$ 
disagree, $4=$ neutral, $5=$ agree, $6=$ strongly agree, $7=$ very strongly agree). The specific constructs and measures in the survey questionnaire are summarized in Appendix A and discussed below.

\section{Information Quality}

To measure information quality, we evaluated the measures proposed by Delone and McLean [2]. In their summary of success measures they listed 23 measures specifically for information quality. We evaluated these measures for their relevance to our particular setting, and selected 7 items that were the most relevant: relevance, redundancy, accuracy, conciseness, readability, ambiguity and timeliness. Two of the measures, timeliness and ambiguity, did not load well on the construct, and they were removed from the analysis. In the context of communication support systems such as WebCT Vista, the information is usually stored in the form of documents, and this is the term that is used in the survey. In each item "the documents" replaced the terms such as "the reports", "the data", and "the information". Higher scores indicate greater information quality.

\section{Simple Task}

While there are several ways to categorize different types of task such as complexity, non-routineness, interdependence, and job title, in this study we do not measure variations of task because this study is based on the fit concept as profile deviation and focuses on a specific profile of simple tasks and a communication technology [43]. The tasks in our study are typical course work tasks: communicating with other students and the instructor, collaborating with other students, scheduling and managing homework, finding and studying information, etc. All these tasks can be categorized as having a single outcome and solution scheme, and are therefore simple tasks.

\section{Communication Technology}

WebCT Vista is an on-line course management system that in our study context is used to support the teaching of a face to face class. Students use the system to find and post information, to submit their work, to track their progress, and to communicate with each other and their instructor. They use the system both during class and between class meetings. The system provides essential communication tools: an email system that is restricted to those that participate in the class, discussion boards, and a chat function. The system also contains all relevant documents for the students (syllabus, lecture notes, links to external sources). It provides a gradebook that students can use to track their performance in the class and it has tools for students to submit their assignments and to take exams and surveys.

Among the three dimensions of technology - communication support, process structuring, and information processing, this study focuses on the communication support oriented technology because simple tasks would be best matched with a technology emphasizing communication support [43]. However, we are also interested in whether the technology supports communications as expected and how different quality of communication support can affect the fit between a simple task and communication technology. Therefore, we include testing the quality aspect of communication technology in the research model.

There have been many dimensions to measure the quality of technology such as reliability, flexibility, ease of learning, response time, and ease of use. We adopt ease of use to measure the quality aspect of communication technology in this study because it has been most widely used in the IS literature [7,9]. Ease of use is defined as the usability of system operating procedures [14]. While Eason's definition of ease of use is somewhat system-focused, ease of use generally refers to "the degree to which a person believes that using a particular system would be free of effort [7]." It is an attribute of an individual's use of a system, rather than of the system per se. Five items for ease of use have been adopted from prior research [7,34]. Higher item scores indicate greater quality of WebCT Vista as a communication technology.

\section{Task Technology Fit}

From Eason's definition of task match [14], task-technology fit as task match can be seen as a function of task and technology because a user can evaluate the degree of task match based on system functionality and task 
requirements. Consequently, evaluating task match means evaluating the functionality of the system by asking users how well the service matches their task requirements. In addition, task match is aligned with the fit as matching, one of the six perspectives on fit by Venkatraman [37]. He proposed that the fit as matching is defined as a match between two theoretically related variables, which are simple task and communication technology in this study, and that the match enhances the performance. We have developed three items for task match, reflecting the definitions of task match [14]. Higher item scores indicate greater fit between task and technology.

\section{Performance}

Individual performance has been measured with perceived usefulness in the IS success literature. Perceived usefulness is defined as "the degree to which the user believes that using a particular system has enhanced his or her job performance" [34]. In this study, we have adapted five measures for perceived usefulness from Rai et al. [34] to measure the impact of using WebCT Vista on performance. Higher item scores indicate greater work performance.

\section{ANALYSIS AND RESULTS}

Partial Least Squares (PLS) analysis (with SmartPLS version 2.0) was used as the primary analysis tool. PLS is an advanced statistical method that allows optimal empirical assessment of a structural model together with its measurement model [42]. PLS first estimates loadings of indicators on constructs, i.e., the measurement model, and then iteratively estimates causal relationships among constructs, i.e., the structural model [7]. PLS is considered preferable to such traditional methods as factor analysis, regression, and path analysis because it assesses both measurement and structural models [19]. In this study, we test two structural models with and without information quality, and compare their results in terms of path coefficients and $\mathrm{R}^{2}$ values to evaluate the effect of information quality in the TTF model.

\section{Measurement Model}

Before testing the structural model, the measurement model must be established by examining the psychometric properties of the measures.

Convergent validity. To evaluate convergent validity of each factor model, we first examined standardized loadings. The standardized loadings should be greater than 0.707 to meet the condition that the shared variance between each item and its associated construct exceed the error variance. As seen in Table 2, all the loadings exceed this threshold. In order to evaluate the internal consistency for each block of measures - construct reliability, we examined Cronbach's alpha, composite reliability, and average variance extracted. The threshold values for Cronbach's alpha and composite reliability are not absolute, but it is suggested that 0.70 indicates extensive evidence of reliability and 0.80 or higher provides exemplary evidence [2, 43]. However, even a score between 0.60 and 0.70 may be acceptable for exploratory research $[27,33]$. As shown in Table 2, all of the constructs in the measurement model exhibited a Cronbach's alpha of 0.865 or higher, and composite reliability of 0.903 or higher. Average variance extracted (AVE) is a way of evaluating the amount of variance that a latent construct "captures from its indicators relative to the amount due to measurement error" [4], which is suggested as a measure of construct reliability [14]. The acceptable level for AVE is 0.5 or higher, meaning that 50 percent or more variance of the indicators is accounted for by the construct [4]. As seen in Table 2, all the AVEs are above the threshold of 0.5. Thus, our evaluations of Cronbach's alpha, composite reliability, and AVE indicate that the construct reliability has been established satisfactorily.

Table 2. Item Loadings and Construct Measurement Properties

\begin{tabular}{|l|l|c|c|c|c|}
\hline \multicolumn{1}{|c|}{ Construct } & \multicolumn{1}{|c|}{ Item } & $\begin{array}{c}\text { Standardized } \\
\text { loading }\end{array}$ & $\begin{array}{c}\text { Cronbach's } \\
\text { alpha }\end{array}$ & $\begin{array}{c}\text { Composite } \\
\text { reliability }\end{array}$ & $\begin{array}{c}\text { Average variance } \\
\text { extracted }\end{array}$ \\
\hline Technology as Ease of & EOU1 & 0.822 & 0.875 & 0.909 & 0.666 \\
Use (EOU) & EOU2 & 0.845 & & & \\
& EOU3 & 0.802 & & & \\
& EOU4 & 0.781 & & & \\
\hline EOU5 & 0.829 & 0.860 & 0.881 & 0.927 & 0.808 \\
\hline
\end{tabular}




\begin{tabular}{|l|l|l|l|l|l|}
\hline & TM2 & 0.931 & & & \\
& TM3 & 0.904 & & & 0.650 \\
Information Quality & IQ1 & 0.755 & 0.865 & 0.903 & \\
& IQ2 & 0.773 & & & \\
& IQ3 & 0.844 & & & \\
& IQ4 & 0.874 & & & \\
& IQ5 & 0.780 & & 0.856 \\
\hline Performance & PERFORM1 & 0.881 & 0.957 & & \\
(PERFORM) & PERFORM2 & 0.945 & & & \\
& PERFORM3 & 0.948 & & & \\
& PERFORM4 & 0.927 & & & \\
& PERFORM5 & 0.924 & & & \\
\hline
\end{tabular}

Discriminant validity. We conducted two tests for discriminant validity. First, each indicator's loading on its own construct and its cross-loadings on all other constructs were calculated. Table 3 shows that each indicator has a higher loading with its intended construct than a cross-loading with any other construct. Moreover, each block of indicators loads higher for its intended construct than indicators from other constructs.

Table 3. Loadings and Cross-Loadings

\begin{tabular}{|l|l|llll|}
\hline \multicolumn{1}{|c|}{ Construct } & Item & $\mathbf{1}$ & $\mathbf{2}$ & $\mathbf{3}$ & $\mathbf{4}$ \\
\hline 1. Technology as Ease of Use (EOU) & EOU1 & $\mathbf{0 . 8 2 2}$ & 0.670 & 0.490 & 0.533 \\
& EOU2 & $\mathbf{0 . 8 4 5}$ & 0.542 & 0.522 & 0.574 \\
& EOU3 & $\mathbf{0 . 8 0 2}$ & 0.607 & 0.572 & 0.571 \\
& EOU4 & $\mathbf{0 . 7 8 1}$ & 0.445 & 0.485 & 0.531 \\
& EOU5 & $\mathbf{0 . 8 2 9}$ & 0.600 & 0.591 & 0.516 \\
\hline 2. Fit as Task Match (TM) & TM1 & 0.548 & $\mathbf{0 . 8 6 0}$ & 0.482 & 0.453 \\
& TM2 & 0.668 & $\mathbf{0 . 9 3 1}$ & 0.543 & 0.521 \\
& TM3 & 0.694 & $\mathbf{0 . 9 0 4}$ & 0.595 & 0.554 \\
\hline 3. Information Quality (IQ) & IQ1 & 0.463 & 0.444 & $\mathbf{0 . 7 5 5}$ & 0.489 \\
& IQ2 & 0.426 & 0.353 & $\mathbf{0 . 7 7 3}$ & 0.487 \\
& IQ3 & 0.544 & 0.498 & $\mathbf{0 . 8 4 4}$ & 0.511 \\
& IQ4 & 0.585 & 0.575 & $\mathbf{0 . 8 7 4}$ & 0.647 \\
& IQ5 & 0.590 & 0.530 & $\mathbf{0 . 7 8 0}$ & 0.550 \\
\hline 4. Performance & PERFORM1 & 0.579 & 0.482 & 0.569 & $\mathbf{0 . 8 7 9}$ \\
& PERFORM2 & 0.657 & 0.526 & 0.642 & $\mathbf{0 . 9 4 4}$ \\
& PERFORM3 & 0.636 & 0.571 & 0.624 & $\mathbf{0 . 9 4 7}$ \\
& PERFORM4 & 0.601 & 0.519 & 0.630 & $\mathbf{0 . 9 2 8}$ \\
& PERFORM5 & 0.609 & 0.533 & 0.641 & $\mathbf{0 . 9 2 6}$ \\
\hline
\end{tabular}

Second, we compared AVE for each construct with the shared variance between all possible pairs of constructs [16]. Table 4 shows that the AVE for each construct is higher than the squared correlation between the construct pairs, which indicates that more variance is shared between the latent construct and its block of indicators than with any other construct representing a different block of indicators. Therefore, the tests above establish discriminant validity.

Table 4. AVEs versus Squares of Correlations between Constructs

\begin{tabular}{|llcccc|}
\hline \multicolumn{1}{|c}{ Construct } & AVE & EOU & TM & IQ & PERFORM \\
\hline Technology as Ease of Use & 0.666 & - & & & \\
Fit as Task Match & 0.808 & 0.509 & - & & \\
Information Quality & 0.650 & 0.427 & 0.365 & - & - \\
Performance & 0.856 & 0.445 & 0.324 & 0.452 & \\
\hline
\end{tabular}

\section{Structural Model}

The structural model was assessed by examining path coefficients and their significance levels. We computed path coefficients in the structural model with the entire sample, and employed the bootstrapping method (with 500 
resamples) to obtain the t-values corresponding to each path. The acceptable t-values for two-tailed tests are 1.96 and 2.58 at the significance levels of 0.05 and 0.01 .

Information quality, the construct that we suggested as another determinant of fit, had a direct positive effect on fit, supporting H1 (path coefficient $=0.24, \mathrm{p}<0.01$ ). Information quality also had a direct effect on perceived usefulness, which is an individual performance measure in the research model. Thus, H2 is supported (path coefficient $=0.52, \mathrm{p}<0.01)$. As for the general TTF model, ease of use as a quality measure for communication technology had a direct effect on fit (path coefficient $=0.56, \mathrm{p}<0.01$ ), which supports H3. Fit also had a positive effect on performance (path coefficient $=0.26, \mathrm{p}<0.01$ ) as originally established by the general TTF model, supporting H4. Thus, all hypotheses in the research model were statistically proved.

The explanatory power of a structural model can be evaluated by examining the variance explained, or $\mathrm{R}^{2}$ value of the final dependent construct. Performance in the model had an $\mathrm{R}^{2}$ value of 0.49 , indicating that the research model accounts for $49 \%$ of the variance in the dependent variable. In addition, we are also interested in the $\mathrm{R}^{2}$ value for task technology fit, the intermediate variable in the structural model. The $\mathrm{R}^{2}$ value for fit in the research model (see Figure 3 ) is 0.54 , which is higher than that of previous TTF studies - e.g., up to 0.24 in [24] and 0.38 in [13]. This increased $\mathrm{R}^{2}$ value stands as compelling evidence of the contribution of information quality to the explanatory power for task technology fit and performance.

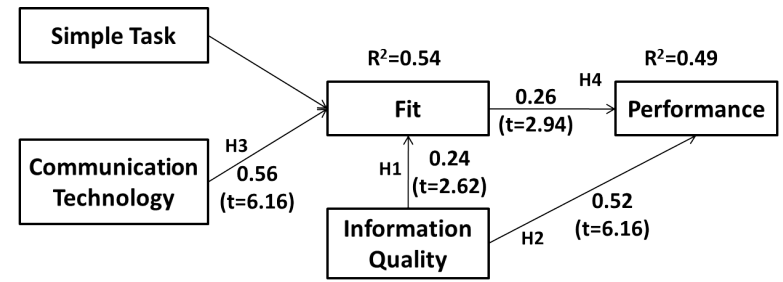

Figure 3. Structural Model

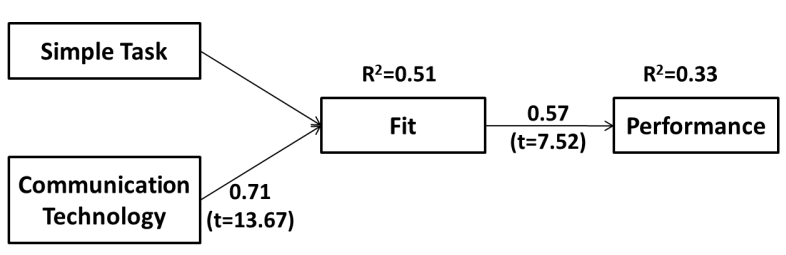

Figure 4. Structural Model without Information Quality

\section{Model Comparison}

In order to test the contribution of information quality to the general TTF model, a structural model without information quality was assessed as shown in Figure 4. The results from two structural models show that the $\mathrm{R}^{2}$ values for task technology fit and performance have been increased from 0.51 and 0.33 to 0.54 and 0.49 , respectively when information quality was added into the TTF model. This implies that information quality is a valid determinant of fit that makes contribution to the explanatory power in the TTF model.

\section{DISCUSSION AND IMPLICATIONS}

This study extends the general TTF model with information quality in the context of a simple task and communication technology. It has implications for both research and practice.

\section{Implications for Research}

The first research contribution of this study is to empirically test information quality as another determinant of fit (Hypothesis 1). Since information systems are used to process, create, and store information, the information is a part of the information systems. And the quality of the information is very important in determining the fit between the task given and the system used to complete the task. As seen in the structural model, the path coefficient of information quality to fit is significant (path coefficient $=0.24, \mathrm{p}<0.001$ ). In addition, information quality contributes to the variance explained for task-technology fit. The $\mathrm{R}^{2}$ value for fit when information quality is included is 0.54 , which is higher than that of previous TTF studies where the $\mathrm{R}^{2}$ ranged from 0.04 to 0.38 [13, 24]. This confirms that information quality plays an important role in determining the fit between a simple task and a communication technology. This factor had not been suggested or tested in prior TTF research. From the results of this study, we would argue that information quality is another valid determinant of fit. 
The second contribution is the confirmation of the effect of information quality on perceived usefulness as an individual performance measure (Hypothesis 2). Seddon [34] suggests that information quality leads to perceived usefulness as a general perceptual measure of the net benefits from IS use. Our structural model confirms that information quality affects perceived usefulness directly as well as indirectly via TTF. This finding empirically supports Seddon's re-specified IS success model.

The third contribution is the reconfirmation of the original TTF model in the context of simple task and communication technology. Our results show that the characteristics of communication technology positively affect the fit between simple task and communication technology (Hypothesis 3). In addition, our analysis confirms that TTF determines perceived usefulness as a measure of individual performance (Hypothesis 4).

The fourth contribution is that this study is the first to empirically test the first proposition in Zigurs and Buckland's [43] theoretical model of fit by quantitatively measuring the task-technology fit between a simple task and a communication technology.

As Zigurs and Buckland [43] suggested, there are fifteen different fit profiles from the combinations of five task types and three technology dimensions (see Table 1). Since this study tested only one fit profile of simple task and communication technology, it would be very interesting if future research can test the suggested TTF model including information quality with other fit profiles. And this would help understand whether the fit perspective, i.e., fit as matching, used in this study is applicable in other fit profiles.

\section{Implications for Practice}

Our inclusion of information quality in the TTF model gives us some important implications for practice. Since information quality contributes to the user perception of fit between task and technology, practitioners should consider a way to control and maintain the quality of information used for the task and stored in the technology. Moreover, information quality directly impacts the user's performance. Thus, quality control for the information used will increase the fit and ultimately lead to the system's success.

When users apply a technology to their task, they may perceive a different fit between the task and the technology depending on the quality of the technology and the type of task. While the task in our study is defined and fixed as a simple task, the quality of the technology may be perceived differently. As shown in the results, ease of use as a quality measure for the communication technology significantly affects the user's evaluation of fit. Thus, the systems developers should consider the quality factors such as ease of use and reliability to increase the user's evaluation of TTF in developing information systems, especially a communication technology.

\section{Limitations and Future Research}

In this study, we tested the fit perspective as matching. While this helps us evaluate the matching perspective of fit in the TTF context, it does not give us a full understanding of how other fit perspectives can be used or incorporated in the TTF research. Thus, testing other fit perspectives in the TTF context would be valuable future research. Such a study would also further validate the use of the matching perspective in the TTF context. In addition, this study employs a limited view of individual performance with perceived usefulness. While usefulness has been widely used to measure performance in the literature, adopting and testing other objective performance measures such as grades would warrant additional future research. Some recent research has applied the concept and model of task technology fit to different types of information systems such as mobile information systems [18] and e-learning systems [30]. Thus, future research can replicate and apply the proposed model in different information systems contexts.

\section{Appendix A. Constructs and Item Measures}

EOU1 - I find it easy to get WebCT Vista to do what I want it to do. / EOU2 - My interaction with WebCT Vista is clear and understandable. / EOU3 - I find WebCT Vista to be flexible to interact with. / EOU4 - I find WebCT Vista easy to use. / EOU5 - WebCT Vista is user friendly. / TM1 - My work in the course is well-supported by WebCT Vista. / TM2 - The functionality of WebCT Vista serves my needs very well. / TM3 - The services provided by 
WebCT Vista match my requirements. / IQ1 - The documents in WebCT Vista are relevant. / IQ2 - The documents in WebCT Vista are not redundant. / IQ3 - The documents in WebCT Vista are accurate. / IQ4 - The documents in WebCT Vista are concise, to the point. / IQ5 - The documents in WebCT Vista are readable. / PERFORM1 - Using WebCT Vista improves my performance in this course. / PERFORM2 - Using WebCT Vista in my coursework increases my productivity. / PERFORM3 - Using WebCT Vista enhances my effectiveness in my coursework / PERFORM4 - Using WebCT Vista makes it easier to do my coursework. / PERFORM5 - I find WebCT Vista useful in my coursework.

\section{REFERENCES}

1. Alavi, M., \& Leidner, D. E. (2001). Review: Knowledge management and knowledge management systems: Conceptual foundations and research issues. MIS Quarterly, 25(1), 107-136.

2. Bearden, W. O., Netemeyer, R. G., \& Mobley, M. F. (1993). Handbook of marketing scales. Newbury Park, CA: Sage.

3. Campbell, D. J. (1988). Task complexity: A review and analysis. Academy of Management Review, 13(1), 4052.

4. Chin, W. W. (1998). The partial least squares approach to structural equation modeling. In G. A. Marcoulides (Ed.), Modern Methods for Business Research (pp. 295-336). Mahwah, NJ: Lawrence Erlbaum Associates.

5. Choi, S. Y., Lee, H., \& Yoo, Y. (2010). The impact of information technology and transactive memory systems on knowledge sharing, application, and team performance: A field study. MIS Quarterly, 34(4), 855-870.

6. Daft, R. L., \& Lengel, R. H. (1986). Organizational information requirements, media richness, and structural design. Management Science, 32(5), 554-571.

7. Davis, F. D. (1989). Perceived usefulness, perceived ease of use, and user acceptance of information technology. MIS Quarterly, 13(3), 319-340.

8. Davis, F. D., Bagozzi, R. P., \& Warshaw, P. R. (1989). User acceptance of computer technology: A comparison of two theoretical models. Management Science, 35(8), 982-1003.

9. DeLone, W. H., \& McLean, E. R. (1992). Information systems success: The quest for the dependent variable. Information Systems Research, 3(1), 60-95.

10. DeLone, W. H., \& McLean, E. R. (2003). The DeLone and McLean model of information systems success: A ten-year update. Journal of Management Information Systems, 19(4), 9-30.

11. Dennis, A. R., Wixom, B. H., \& Vandenberg, R. J. (2001). Understanding fit and appropriation effects in group support systems via meta-analysis. MIS Quarterly, 25(2), 167-193.

12. DeSanctis, G., \& Poole, M. S. (1994). Capturing the complexity in advanced technology use: Adaptive structuration theory. Organization Science, 5(2), 121-147.

13. Dishaw, M. T., \& Strong, D. M. (1999). Extending the technology acceptance model with task-technology fit constructs. Information and Management, 36(1), 9-21.

14. Eason, K. (1988). Information technology and organizational change. London: Taylor and Francis.

15. Fornell, C., \& Bookstein, F. L. (1982). Two structural equation models: LISREL and PLS applied to consumer exit-voice theory. Journal of Marketing Research, 19(4), 440-452.

16. Fornell, C., \& Larcker, D. F. (1981). Evaluating structural equation models with unobservable variables and measurement error. Journal of Marketing Research, 18(1), 39-50.

17. Fuller, R. M., \& Dennis, A. R. (2009). Does fit matter? The impact of task-technology fit on team performance for repeated tasks. Information Systems Research, 20(1), 2-17.

18. Gebauer, J., Shaw, M. J., \& Gribbins, M. L. (2010). Task-technology fit for mobile information systems. Journal of Information Technology, 25, 259-272.

19. Gefen, D., Straub, D. W., \& Boudreau, M.C. (2000). Structural equation modeling and regression: Guidelines for research practice. Communications of the Association for Information Systems, 4(7), 1-30.

20. Gold, A. H., Malhotra, A., \& Segars, A. H. (2001). Knowledge management: An organizational capabilities perspective. Journal of Management Information Systems, 18(1), 185-214.

21. Goodhue, D. L. (1995). Understanding user evaluations of information systems. Management Science, 41(12), 1827-1844.

22. Goodhue, D. L. (1998). Development and measurement validity of a task-technology fit instrument for user evaluations of information systems. Decision Sciences, 29(1), 105-138. 
23. Goodhue, D. L., Barbara, D. K., \& Salvatore, T. M. (2000). User evaluations of IS as surrogates for objective performance. Information and Management, 38(2), 87-101.

24. Goodhue, D. L., \& Thompson, R. L. (1995). Task-technology fit and individual performance. MIS Quarterly, 19(2), 213-236.

25. Gray, P. H., \& Durcikova, A. (2006). The role of knowledge repositories in technical support environments: Speed versus learning in user performance. Journal of Management Information Systems, 22(3), 159-190.

26. Gray, P. H., \& Meister, D. B. (2004). Knowledge sourcing effectiveness. Management Science, 50(6), 821-834.

27. Hair, J. F., Anderson, R. E., Tathem, R. L., \& Black, W. C. (1998). Multivariate data analysis (Fifth ed.). Upper Saddle River, New Jersey, U.S.A.: Prentice Hall.

28. Kankanhalli, A., Tan, B. C. Y., \& Wei, K. (2005). Contributing knowledge to electronic knowledge repositories: An empirical investigation. MIS Quarterly, 29(1), 113-143.

29. Klopping, I. M., \& McKinney, E. M. (2004). Extending the technology acceptance model and the tasktechnology fit model to consumer e-commerce. Information Technology, Learning, and Performance Journal, 22(1), 35-48.

30. Lin, W.S., \& Wang, C.H. (2011). Antecedences to continued intentions of adopting e-learning system in blended learning instruction: A contingency framework based on models of information system success and task-technology fit. Computers \& Education, 58, 88-99.

31. Mathieson, K., \& Keil, M. (1998). Beyond the interface: Ease of use and task/technology fit. Information and Management, 34(4), 221-230.

32. McGill, T., \& Klobas, J. E. (2009). A task-technology fit view of learning management system impact. Computers \& Education, 52(2), 496-508.

33. Nunnally, J. C. (1967). Psychometric theory. New York: McGraw-Hill.

34. Rai, A., Lang, S. S., \& Welker, R. B. (2002). Assessing the validity of IS success models: An empirical test and theoretical analysis. Information Systems Research, 13(1), 50-69.

35. Seddon, P. B. (1997). A respecification and extension of the DeLone and McLean model of IS success. Information Systems Research, 8(3), 240-253.

36. Staples, D. S., \& Seddon, P. (2004). Testing the technology-to-performance chain model. Journal of Organizational and End User Computing, 16(4), 17-36.

37. Turner, J. M., Biros, D. P., \& Moseley, M. W. (2009). KMS-Fit: A case-based exploration of task/technology fit in an applied knowledge management context. Knowledge Management \& E-Learning: An International Journal, 1(2).

38. Venkatraman, N. (1989). The concept of fit in strategy research: Toward verbal and statistical correspondence. Academy of Management Review, 14(3), 423-444.

39. Venkatesh, V., \& Davis, F. D. (2000). A theoretical extension of the technology acceptance model: Four longitudinal field studies. Management Science, 46(2), 186-204.

40. Venkatesh, V., Morris, M. G., Davis, G. B., \& Davis, F. D. (2003). User acceptance of information technology: Toward a unified view. MIS Quarterly, 27(3), 425-478.

41. Wasko, M. M., \& Faraj, S. (2005). Why should I share? Examining social capital and knowledge contribution in electronic networks of practice. MIS Quarterly, 29(1), 35-57.

42. Wold, H. (1982). Soft modeling: The basic design and some extensions. In K. G. Joreskog \& H. Wold (Eds.), Systems under Indirect Observation (Vol. 2, pp. 1-54). Amsterdam: North-Holland.

43. Yi, M. Y., \& Davis, F. D. (2003). Developing and validating an observational learning model of computer software training and skill acquisition. Information Systems Research, 14(2), 146-169.

44. Zigurs, I., \& Buckland, B. K. (1998). A theory of task/technology fit and group support systems effectiveness. MIS Quarterly, 22(3), 313-334.

45. Zigurs, I., Buckland, B. K., Connolly, J. R., \& Wilson, E. V. (1999). A test of task-technology fit theory for group support systems. The Database for Advances in Information Systems, 30(3/4), 34-50.

46. Zigurs, I., \& Khazanchi, D. (2008). From profiles to patterns: A new view of task-technology fit. Information Systems Management, 25(1), 8-13. 